\title{
TCR gene-modified cells: past promises, present methodologies and future challenges
}

\author{
Rita Tendeiro Rego, Emma C Morris, Mark W Lowdell
}

Keywords: adoptive cell therapy (ACT); gene therapy; immunotherapy; TCR-modified cells

\begin{abstract}
Immunotherapy constitutes an exciting and rapidly evolving field, and the demonstration that genetically-modified T cell receptors (TCRs) can be used to produce T lymphocyte populations of desired specificity offers new opportunities for antigen-specific T cell therapy.

Overall, TCR-modified T cells have the ability to target a wide variety of self and non-self targets through the normal biology of a T cell. Although MHC-restricted and dependent on co-receptors, genetically engineered TCRs still present a number of characteristics that ensure they are an important alternative strategy to chimeric antigen receptors (CARs), and high affinity TCRs can now be successfully engineered with the potential to enhance therapeutic efficacy while minimising adverse events.

This review will focus on the main characteristics of TCR gene-modified cells, their potential clinical application and promise to the field of adoptive cell transfer (ACT), basic manufacturing procedures and characterisation protocols, and overall challenges that need to be overcome so that redirection of TCR specificity may be successfully translated into clinical practice, beyond early phase clinical trials.
\end{abstract}

\section{Background}

With roots in the principles of basic immunology, synthetic biology and genetic engineering, the field of adoptive cell transfer (ACT) has become one of the most promising and innovative approaches to treat cancer, viral infections and other immune-modulated diseases.

There are currently three main types of ACT using effector $T$ cells ${ }^{1}$ : administration of tumour infiltrating lymphocytes (TILs), and gene transfer-based strategies relying on genetic engineering to express either chimeric antigen (Ag) receptors (CARs) - composed of antibody (Ab)-binding domains fused to T cell signalling domains - or engineered T cell receptor (TCR) $\alpha / \beta$ heterodimers.

Genetic modification of autologous T cells to target specific tumour antigens has been developed to overcome the consequences of immune tolerance and offers the possibility to endow the immune system with reactivities not naturally present. This approach has the additional benefit of rapid tumour eradication, which is usually observed with cytotoxic chemotherapy or other targeted therapies rather than the delayed responses that are commonly observed with vaccines and $T$ cell checkpoint therapies. 
Durable anticancer responses have been extensively reported for CARs targeting CD19 in the treatment of acute lymphoblastic leukaemia (ALL), B-cell lymphomas ${ }^{2}$ and chronic lymphocytic leukaemia (CLL), and the US Food and Drug Administration (FDA) has recently approved two genetically engineered CD19 CAR T cell products, tisagenlecleucel (Kymriah) ${ }^{3}$ and axicabtagene ciloleucel (Yescarta) ${ }^{4}$, for clinical application. Therapeutic TCR gene-modified T cells have demonstrated clinical activity in earlier phase clinical trials but their development currently lags behind CAR T cells ${ }^{2}$. The unique biology of TCR-peptide/MHC recognition may render TCR-modified T cells a more suitable approach for specific types of malignancies, including solid tumours due to their ability to recognise low concentrations of cognate antigen including peptides derived from intracellular antigens.

\section{TCR structure and signalling}

An extensive body of work exists elucidating the details underlying TCR structure, engagement and signalling (reviewed in ${ }^{5-8}$ ), which provides the basis for the development of TCR-modified T cells (reviewed in ${ }^{9,10}$ ). Briefly, the TCR is a heterodimeric protein receptor, typically consisting of an alpha $(\alpha)$ and a beta $(\beta)$ chain, expressed on the cell surface as part of a complex with CD3 molecules. A minority of T cells can express an alternate receptor formed by gamma $(\gamma)$ and delta $(\delta)$ chains $(\gamma \delta T$ cells). TCR activation depends on the binding to a processed intracellular peptide presented by a major histocompatibility complex (MHC) molecule (the peptide-MHC complex) on the target cells, followed by proper signal initiation and amplification, processes that involve an array of cell surface ligands and receptors on both the target cell and the T cells.

Each $\alpha$ and $\beta$ chain contains variable (V) and constant $(C)$ regions, with the latter being followed by a transmembrane region. Each $V$ domain contains three loops (CDR1, CDR2 and CDR3) which interact with the peptide-MHC complex ${ }^{11}$. As the $\alpha \beta$ heterodimer lacks its own intracellular signalling domains. Therefore, it must associate with the six-subunit CD3 complex, which contains a total of ten immunoreceptor tyrosine-rich activation motifs (ITAMs) that are responsible for signal transduction ${ }^{11}$ (Figure 1).

TCR engagement is necessary but not sufficient for complete T cell activation and triggering of effector function (i.e. proliferation, differentiation, survival and cytokine production) and a second signal is required, which is provided by co-stimulatory molecules, such as CD28, CD80 and CD86 ${ }^{12}$ (also Figure 1).

T cells can be activated in vitro by binding of the TCR to as few as four to ten peptide-MHC molecules $^{13,14}$ a feature that is partly accomplished by the action of CD4 and CD8 co-receptor molecules. CD4 is expressed on the surface of T helper (Th) and regulatory T cells (Treg) and is required for recognition of class II MHC. CD8, on the other hand, is expressed on cytotoxic T lymphocytes (CTLS) 
and is required for the optimal recognition of class I MHC. The functional synergy between TCR and co-receptors is based on binding to invariant regions of MHC molecules and association of the cytoplasmic tails with protein kinases involved in ITAM-mediated signal transduction (e.g. Lck), once brought into close proximity of the TCR/CD3 complex ${ }^{15}$.

The ultra-sensitivity and capacity for fine tuning of the TCR system provides the potential to target very low concentrations of intracellular antigens. Additionally, the ability to recognise almost any intracellular protein via the MHC system allows TCRs to target more antigens than can antibodies (or scFv-CARs), which recognise only cell surface antigens.

\section{Clinical application of TCR-modified cells}

Reviews have recently been published describing outcomes following TCR gene therapy clinical trials $^{16-19}$, which, to date, have been mostly limited to MHC-I-restricted therapeutic TCRs targeting peptides presented by HLA-A*0201, which is found in approximately $45 \%$ of Caucasians. Table 1 features a summary of current and past TCR modified T cell trials registered on clinicaltrials.gov, with the majority of applications to date in cancer.

However, as T cells are also essential for the control of viral infection and can be equally successfully engineered to express virus-specific TCRs (e.g. anti-CMV, -EBV, -HIV and -HBV TCRs) ${ }^{20-23}$, there is a trend towards designing novel therapeutic strategies for both viral infectious diseases and virusassociated malignancies in patients whose autologous T cell repertoire lacks the relevant specificities.

\section{Cancer}

Over a decade ago, Rosenberg et al reported for the first time that metastatic melanoma patients treated with lymphocytes genetically engineered to express a TCR specific for a melanocytedifferentiating antigen (MART-1), demonstrated long-term persistence of infused cells and tumour regression in 2 of 17 patients ${ }^{24}$. Subsequent studies further demonstrated that TCR gene-modified T cells were generally safe, well tolerated, and had the potential to be effective therapeutically in cancer patients ${ }^{25,26}$, whilst also highlighting the potential for serious adverse events, including destruction of normal melanocytes in the skin, eye and year ${ }^{26}$, and also death ${ }^{27}$.

Identification and sequencing of TCRs able to recognise epitopes expressed by human tumours together with improvements in TCR gene transfer technology have allowed for rapid redirection of T cells and targeting of a variety of tumour antigens, including $\mathrm{gp} 100^{28}, \mathrm{p} 53^{29}$, carcinoembryonic antigen $(C E A)^{28}$, cancer-testis antigen (CTA) family members (e.g. NY-ESO-1 ${ }^{30}$, MAGE-A3 ${ }^{31}$, MAGE-A4 ${ }^{32}$ and MAGE-A $\left.10^{33}\right)$, and viral protein family members ${ }^{34,35}$.

Importantly, all completed and ongoing TCR gene therapy trials target either cancer testis antigens with restricted tissue expression in adult cells or tumour-associated antigens that are also expressed 
to various extents in normal tissues (Table 1). This physiological expression of TCR-targeted antigens poses the risk of "off-tumour/on-target" immune pathology, such as that observed with TCR-targeting of MART-1, which is discussed in more detail in the next section. To better identify potential target antigens, in silico proteome searches may be performed, which analyse target peptides for structural uniqueness ${ }^{36,37}$. This type of analysis could also potentially help identify "off-tumour/off-target" toxicities associated with self-peptide/MHC antigens that could pose problems with cross-reactivity ${ }^{11}$.

\section{Viral infections and virus-associated malignancies}

Adoptive transfer of in vitro-expanded autologous or allogeneic virus-specific T cells have shown remarkable efficacy in preventing CMV and EBV reactivation after haematopoietic stem cell transplantation (HSCT) in immunocompromised patients ${ }^{38-40}$, and virus-specific T cells have also been described as playing a critical role in immune control in the context of both $\mathrm{HBV}^{41}$ and $\mathrm{HIV}^{42}$ infections. Nevertheless, whilst virus-specific TCR-modified T cells have shown protective capacity in animal models ${ }^{43}$, in humans the suitability of such cells for use in clinical application is yet to be fully demonstrated, with one phase I study assessing safety and toxicity of HLA-A*0201 restricted CMV pp65-specific TCR transduced donor derived T cells in CMV seropositive recipients following allogeneic HSCT from CMV seronegative donors yet to report (NCT02988258).

Joseph et al demonstrated that polyclonal $\mathrm{CD} 8^{+} \mathrm{T}$ cells could be redirected to target HIV-infected cells upon transduction with a lentivirus expressing the HIV Gag-specific SL9 TCR, which recognises an HLA$A^{*}$ 02-restricted P17 epitope and T cell clones with this specificity have been identified in the peripheral blood of patients and is associated with lower plasma virus levels during chronic HIV infection ${ }^{44}$. In a preclinical model, these cells were able to lyse A2-SL9-expressing target cells and significantly reduce HIV infection in a SCID mouse model of HIV infection, and a clinical trial was initiated to examine the effects of infusing unmodified or affinity enhanced SL9 TCR-transduced T cells in HIV-infected patients (NCT00991224, Table 1). However, off-target toxicity resulting in the death of two participants in a different trial with an affinity-enhanced HLA-A*01 restricted MAGE-A3-specific TCR for myeloma and melanoma patients ${ }^{37}$ caused concern over the ability of investigators to predict and model the target specificity of affinity enhanced TCRs, and NCT00991224 was closed before any patient received any transduced T cells ${ }^{45}$.

Approximately $15-20 \%$ of all cancers worldwide are associated with infection, the majority associated with viral infection ${ }^{35}$, whilst bacteria and multicellular parasites are responsible for only a fraction of these infection-related cancers ${ }^{46}$.

A case report published in 2015 showed that administration of HBV(HBs183-91)-specific TCR-modified T cells to a patient with HBV-related hepatocellular carcinoma $(\mathrm{HCC})$ caused a substantial reduction in the levels of HBsAg produced by DNA integrated in $\mathrm{HCC}$ cells ${ }^{47}$. Whilst clinical efficacy was not established in this subject, as treatment occurred in the setting of end-stage metastatic disease, the 
authors confirmed the feasibility of providing autologous TCR-redirected therapy against HCC and advocated the strategy employed as a novel therapeutic opportunity in hepatitis B-associated malignancies. However, toxicity concerns hampered the implementation of this approach for the treatment of chronic HBV infection, as the generated TCR-modified T cells were not able to exclusively lyse HBV-infected hepatocytes, and the infusion of HBV-specific cytotoxic T lymphocytes (CTLS) into HBV transgenic mice had also been shown to trigger inflammatory events within the liver, thereby possibly contributing to amplify the severity of liver disease $\mathrm{e}^{48,49}$.

In the setting of HPV-associated epithelial cancers including cervical, oropharyngeal, vaginal and anal carcinomas (NCT02280811, Table 1), TCR-modified T cells targeting the HPV-16 derived E6 peptide have been shown to be safe at doses up to $2 \times 10^{11}$ cells. Regression of metastatic HPV+ carcinoma was also observed in two patients following treatment, suggesting this TCR T cell therapy to able to mediate epithelial cancer regression. Currently, another trial (NCT02858310) is testing the safety and efficacy of administering HPV E7-specific modified T cells.

\section{TCR-modified cell-associated toxicities}

To support the wider clinical application of TCR-modified T cells, it is important that risks can be appropriately identified and mitigated, preferably at the pre-clinical level.

The toxicity observed to date with the administration of TCR-modified T cells is similar to that observed during standard ACT and can be grossly divided into three main groups: toxicity due to the lymphodepleting preparation regimen, cytokine-related toxicity and immune-related toxicity.

\section{Lymphoproliferative preparation regimen}

Most clinical protocols with TCR gene therapy have incorporated preconditioning of the patient with a lymphodepleting regimen prior to $\mathrm{T}$ cell infusion ${ }^{50}$. This aims at both facilitating engraftment and homeostatic expansion and thus improving persistence of the modified T cells. Additionally, IL-2 administration following $\mathrm{T}$ cell infusion has been used to promote infused cell persistence and proliferation in the majority of trials ${ }^{51}$.

Lymphodepleting preparative regimens typically result in transient cytopenias and the supportive IL2 infusions can cause a variety of side effects, including chills, high fever, hypotension, oliguria and edema due to the systemic inflammatory and capillary leak syndrome effects (if high doses IL-2 are used) and can usually be treated with supportive measures ${ }^{51}$.

\section{Cytokine related toxicities}

Highly proliferative T cells can lead to cytokine release syndrome (CRS), which may range from high fever and myalgia to unstable hypotension and respiratory failure. A key insight into CRS came with 
the observation that, in addition to the expected effector cytokines such as interferon (IFN)-gamma, interleukin (IL)- 6 can be secreted at significantly elevated levels during the exponential phase of CAR T cell therapy ${ }^{52}$. CRS is directly and possibly causally related to a complementary toxicity, which is macrophage activation syndrome ${ }^{53}$. These insights have resulted in a therapeutic option for severe CRS, which is IL-6 blockade using the IL-6 receptor antagonist tocilizumab ${ }^{1}$. CRS rates following TCRmodified T cells have been lower than that observed after CAR T cells.

Emergence of neurologic symptoms, which are varied but self-limiting, including delirium, dysphasia, akinetic mutism, and seizures, has also been reported after infusion of T cells engineered with an HLAA2-restricted MAGE-A3-specific TCR ${ }^{54}$. This was probably due to a TCR-mediated inflammatory response that resulted in neuronal cell destruction and raises caution for clinical applications targeting MAGE-A family members with highly active immunotherapies.

Immune-related toxicity: "off-tumour/on-target" effects

The optimal gene-engineered T cell therapy target antigen is one that is only present on the tumour cell and absent in healthy cells; however, in most cases the selected tumour target antigens are overexpressed or aberrantly expressed proteins that may therefore be present to varying extent in normal cells ${ }^{55}$. Gene engineered T cell therapies may, therefore, trigger a potent cellular immune response against normal cells, even those that express the target antigens at low levels ${ }^{55}$. This type of toxicity is known as "off-tumour/on-target" due to the engineered T cells being unable to distinguish between normal cells and cancer cells that express the targeted antigen.

Targeting of MART-1 has been associated with significant "on-target/off-tumour" side effects"27,55. Specifically, a case report has been published describing a fatal serious adverse event three days after transduced T cell administration with a MART-1-specific TCR to a patient with metastatic melanoma ${ }^{27}$. Infused T cells were recovered from blood, broncho-alveolar lavage, ascites, tumour sites and heart tissue, and although no cross-reactivity of the modified T cells toward a 3D beating cardiomyocyte culture was observed, the authors were not able to exclude the possibility of cross-reactivity with an allogeneic MHC-peptide complex. Additionally, multiple organ failure was found to be due to on-target cytokine release.

\section{Immune-related toxicity: "off-tumour/off-target" effects}

Because most tumour antigens are derived from self-proteins (tumour associated antigens), the isolation of high-affinity tumour-specific $T$ cells is effectively precluded by thymic selection. TCR affinity can, nevertheless, be considerably enhanced through mutation of specific regions within the complementarity-determining regions (CDRs) ${ }^{56,57}$. Although useful to promote modified T cell efficacy, 
due to TCR degeneracy ${ }^{58}$, this approach carries the risk that a TCR might recognise other related peptide antigens presented on normal tissue through cross-reactivity.

Additionally, TCR mispairing between the introduced TCR alpha and beta chains with the endogenous beta and alpha chains, respectively, can result in novel TCR chains with unknown and potentially autoreactive specificities (Figure 2, adapted from $^{59}$ ). To reduce this risk, a number of strategies have been developed for the design of genetically-modified TCRs, including the use of additional cysteine bonds between the constant regions of the TCR chains, and murinisation of the constant regions.

Previously published results have shown lethal toxicities in two patients, who were infused with T cells engineered to express a TCR targeting melanoma-associated antigen MAGE-A3 cross-reacting with a peptide from the muscle protein Titin, even though no cross-reactivities had been predicted in the pre-clinical studies ${ }^{37,54}$. These patients demonstrated that TCR-engineered T cells can have serious and not readily predictable off-target and organ-specific toxicities and highlight the need for improved methods to define the specificity of engineered TCRs. Strategies such as peptide scanning and the use of more complex cell structures are therefore recommended in pre-clinical studies to mitigate the risk of off-target toxicities in future clinical investigations ${ }^{54}$. Paradoxically, the use of lower affinity TCR for tumour-related antigens may reduce off-tumour activity due to the lower levels of antigen expression on normal cells.

\section{Manufacturing procedures}

We have recently manufactured TCR-engineered T cells to GMP for clinical trial NCT02988258 using a retroviral vector that specifically incorporates a number of safety features for clinical application (see details in the following sub-sections). The methods used in our facility are standard and wellestablished for manual/open retroviral transduction of primary cells, and have previously been used for manufacture of specific TCR-transduced cells for another clinical trial (NCT01621724). A total of four product manufacturing procedures have been performed to GMP (three validation runs and one product for patient administration), with transduction efficiencies above $30 \%$ in the CD3+ compartment, as determined by flow cytometry for cell surface $V \beta$ expression.

Retroviral vectors were the first viral vectors used for clinical application and are still used as genetransfer vehicles in about $20 \%$ of the current clinical trials ${ }^{60}$. The wide usage of retroviral vectors is due to their broad cell tropism, efficient integration and stable gene expression in target cells. In addition, they can be consistently manufactured at relatively low cost.

\section{Retroviral vector design}

As discussed, the ability to redirect $T$ cells to recognise a specific antigen is not enough to ensure an effective immunotherapy, and therefore antigen recognition needs to be coupled with efforts to 
ensure maximal expression of the therapeutic TCR and enhancement of antigen-specific function whilst limiting off-target or off-tumour recognition. T cells should also be able to persist long-term and traffic to and accumulate at the target site. Additionally, optimally modified T cells should exhibit robust, multi-functional immune responses, resist mechanisms of anergy, exhaustion and immunosuppression within the tumour microenvironment, and be susceptible to deletion on demand to diminish potential toxicity issues ${ }^{9}$.

As a heterodimer, two TCR chains ( $\alpha$ and $\beta$ ) need to be expressed and correctly assembled at the cell surface to redirect specificity. This requires large constructs with multiple genes and may result in potentially non-uniform TCR chain expression ${ }^{9}$. The presence of endogenous TCRs also allows for the opportunity of chain mispairing between endogenous and introduced $\alpha$ and $\beta$ chains, with a TCRtransduced T cell therefore having the potential to express four distinct TCRs, only one of which is desired (Figure 2$)^{59}$. Because these interactions may reduce the level of expression of the introduced TCR and lead to novel, unpredictable and potentially dangerous target specificities through mispairing, it is important that vector design aims at maximising the level of introduced TCR expression and equimolar expression of both TCR $\alpha$ and TCR $\beta$ chains.

A schematic representation of the retroviral vector construct used for clinical trial NCT02988258 is shown in Figure 3. To help promote efficient translation and surface assembly of the introduced receptor without altering the TCR sequence itself ${ }^{9}$, TCR $\alpha$ and $\beta$ chains were codon optimised and linked via an internal self-cleaving porcine teschovirus $2 \mathrm{~A}$ sequence. A leader sequence (LS) was also incorporated, from which all "start" codons were removed, thereby decreasing the risk of possible protein/peptide production and reduce the likelihood of homologous recombination with endogenous retroviral sequences ${ }^{61}$. To enhance gene expression and minimise mispairing with endogenous TCR chains, an additional cysteine residue ${ }^{62}$ was engineered into each one of the constant regions.

Furthermore, because human-murine hybrid TCRs have been described not only to preferentially pair and effectively compete for human CD3 molecules but also to mediate higher levels of cytokine secretion in vitro ${ }^{63,64}$ when introduced into primary human T cells ${ }^{64-66}$, both $\alpha$ and $\beta$ constant regions were replaced with murine sequences. However, the use of TCRs containing murine sequences gives rise to the possibility for anti-murine immune responses which may limit the persistence of these $T$ cells.

\section{Transduction protocol and in process controls}

Manufacture of T cells genetically engineered to express the specific TCR required for the NCT02988258 clinical trial is initiated from density gradient-purified peripheral blood mononuclear cells (PBMCs) in a closed system (COBE 2991 cell processor). T cell activation is first carried out in gaspermeable cell bags using clinical grade microbeads conjugated with anti-CD3 and anti-CD28 
antibodies for 48 hours. One round of transduction is then performed with the retroviral vector in bags pre-coated with RetroNectin, which promotes co-localization of the retroviral vector with the target cells to enhance transduction efficiency. Activated cells are exposed to the viral supernatant for up to 72 hours, after which activating beads are removed, and the cells washed and resuspended in cell culture medium for an overnight incubation. At the end of the 6-day production run, the cells are cryopreserved for later administration after QC testing and QP certification for batch release. Purification of TCR-transduced T cells is not performed, and bulk TCR transduced cells are therefore administered to the patients. This is because this procedure aims at keeping the in vitro manipulation and culture period to a minimum in order to preserve maximum $\mathrm{T}$ cell function.

This semi-closed, small-scale manufacturing platform takes a maximum of 6 days, successfully supports an ongoing clinical trial and can be easily adapted for other clinical trials involving the transduction and expansion of either autologous or donor T cells.

All donors are screened for infectious disease markers as per 2006/17/EC (as amended), and the cells are monitored throughout the procedure to collate information on sterility, viability, and cell count. Appropriate bead removal ( $<1$ bead $/ 1 \times 10^{6}$ cells) is confirmed by microscopy. A sample of the final TCRtransduced product is withheld to test for replication-competent retrovirus (RCR) in case of reported related serious adverse events.

\section{Release testing of the product}

An appropriate set of practical and scientifically defendable release criteria is essential to guarantee the products' integrity, consistency and efficacy. The underlying principle for release criteria is to provide adequate testing to ensure the product's identity (which, in the case of T cell products, is commonly assessed by flow cytometry analysis), purity (i.e. absence of microbeads and non-T cells or other contaminants), safety (i.e. no bacterial/fungal and/or mycoplasma contamination and lack of RCR and endotoxin) and potency (which, in the case of genetically-modified products, may simply correspond to a minimum viability and transduction efficiency for products in early stage trials) ${ }^{60}$.

Release testing of our product includes assessment of sterility (no bacterial contamination assessed by BacTec automated-based methods and Gram stain), viability (>80\%), cell count (dose-dependent) and evaluation of transduction efficiency (5-70\%).

To determine the percentage of T cells effectively expressing the introduced TCR, transduced cells are stained with antibodies against $C D 3, C D 8, C D 4$ and the $V \beta$ chain of interest (i.e. the $V \beta$ chain included in the retroviral vector construct). However, the introduced $V \beta$ chain may also be used by some endogenous TCRs that are not specific for the intended target. To determine the percentage of T cells expressing endogenous $V \beta$, non-transduced $T$ cells (which are kept as negative controls alongside the transduced ones throughout manufacture but are not exposed to the retroviral vector) are also stained with antibodies against CD3, CD8, CD4 and V $\beta$. Transduction efficiency is obtained by 
subtracting the percentage of $\mathrm{V} \beta$-expressing cells in the negative control from the overall frequency of $\mathrm{V} \beta+$ cells in the transduced population.

Staining with anti-murine constant beta $(\mathrm{mCb})$ chain antibodies (where relevant) and/or HLAA*0201/peptide tetramers or multimers, which identify only the T cells expressing the introduced TCR, may also be used to assess transduction efficiency. However, tetramer staining is based on low affinity interactions that might be susceptible to small changes in the density of the TCR ligand and, as such, it is common for TCR-transduced T cells to bind tetramer poorly immediately after transduction, despite displaying antigen-specific effector function on stimulation with cognate antigen. This may be because T cell activation involves multiple receptor/ligand interactions, including ligation of the TCR, CD8 co-receptor, co-stimulatory molecules such as CD28 and accessory molecules, which may render this activation pathway less susceptible to small reductions in the amounts of TCR expressed by the responding T cells.

Release of the cell product for infusion is handled through the issuance of a QP certification form and a certificate of analysis (COA) summarising the characteristics of the product and the tests performed. The CoA also details the release specifications and results of each test, including the method used and acceptable range of results ${ }^{60}$.

\section{The importance of potency assays}

According to the IHC guideline $6 \mathrm{QB}$, potency is the quantitative measure of biological activity using a suitable quantitative biological assay (also called potency assay or bioassay), based on the characteristic of the product which is linked to its relevant biological properties ${ }^{67}$. It constitutes a quality attribute for any biological product, and the implementation of relevant assays is often at the centre of many challenges and discussions amongst developers and regulators throughout product development. Potency assessment is important, as a tool to assess product quality and consistency during manufacturing, but also for clinical development, as it helps predict the product's clinical efficacy by creating a link to the dose.

A review on potency assay development for cellular therapy products has been previously published ${ }^{68}$. For cell-based immunotherapy products ${ }^{69,70}$, including those containing genetically modified cells ${ }^{71}$, the development of adequate potency assays may be complicated by multi-antigen formulations and the inherent variability of the starting material; therefore, a combination of methods may be advisable for appropriate functional characterisation. To estimate the potency of transduced cells, biological tests should be applied to determine the functional properties achieved by the genetic modification. Potency can be expressed as a combination of several parameters including the number of genetically modified cells, gene copy number, expression level of the transgene and the product activity level, as shown to be efficacious in clinical studies ${ }^{71}$. 
One of the requirements included in Directive 2003/63/EC (Annex I, part IV) is that human somatic cell therapy medicinal products are made of a defined number of viable cells. Cell viability is, therefore, an important parameter of product integrity and may be used as an in-process control after manipulation of certain cell characteristics ${ }^{70}$. Cell viability may also be an important element of the potency of cell-based products, but it should be linked to other measures of potency that demonstrate the potential for biological activity of the product, such as quantitative antigen expression or biological activity as measured in the bioassay ${ }^{70}$.

For genetically modified cells, detection of transgene presence and expression allows for the development of highly specific potency assays. Whereas for unmodified cells, potency evaluation strategies typically rely on a large variety of markers and biomolecules.

In vitro assays allow the measurement of biochemical and/or physiological responses at the cellular level. Such assays are generally suitable as a direct measure of the biological activity for characterisation when they correlate with the intended therapeutic effect. Measurable biological activities are, for example, in vitro lysis of target cells by tumour-specific (CD8) T cells, in vitro cytokine production by specific cells and co-stimulatory capacity of dendritic cells (DC)s. Indirect measures of potency can also be used, provided that a correlation between the surrogate and the defined biological activity has been demonstrated (eg. determination of cell surface markers, activation markers, secretion of factors, expression of a single gene product or protein expression patterns) ${ }^{70}$.

\section{Alternative manufacturing procedures}

Development and GMP manufacture of TCR-engineered cells are highly dependent on the type of product required, the most suitable method of gene transfer, and the overall intended scale of the procedure (final T cell dose). The sections below describe some alternative approaches to the design and production of TCR-modified cells.

\section{Vector systems}

Amongst the different types of gene vector systems available, retroviral and lentiviral vectors have become state-of-the-art technology for gene transfer into human lymphocytes.

Lentiviral vectors share some similarities with their retroviral counterparts, such as efficient gene transfer, high levels of transgene expression and broad tropism, whilst introducing a number of advantageous characteristics like the ability to transduce non-dividing cells and a safer chromosome integration profile ${ }^{60}$. They have also been successfully used to engineer hematopoietic stem cells for the treatment of a number of conditions ${ }^{72-77}$.

The sleeping beauty (SB) transposon/transposase system is a relatively new technology in the gene therapy field. This is a double plasmid-based methodology, where one plasmid is the transposon 
encoding the gene of interest (e.g. TCR or CAR), and the second plasmid expresses the transposase that enables the insertion of the transgene into TA dinucleotide repeats. Plasmids are introduced into $T$ cells by electroporation, and transfected cells subsequently expanded on artificial antigenpresenting cells ${ }^{78,79}$. Advantages of using the SB system include the increased simplicity of clinicalgrade plasmid manufacture and the cost effectiveness due to lesser safety testing requirements when compared to cell products genetically modified with retroviral or lentiviral vectors due to permanent gene integration ${ }^{60}$.

\section{Construct design}

Additional specific modifications can be introduced in vector constructs to try and maximise engineered T cell function, by influencing TCR expression levels and TCR affinity.

Affinity and expression levels of therapeutic TCRs are two key parameters that determine how much antigen is needed for the triggering of $T$ cell function. Besides the already discussed codon optimization, introduction of an additional disulphide bond between the TCR chains, and the introduction of murine residues into the constant region domains, several other engineering strategies may be employed to prevent mispairing and further enhance both the level of introduced ('therapeutic') TCR expression on the T cell surface and antigen-specific effector functions. These include 1) provision of additional CD3 molecules ${ }^{80}, 2$ ) addition of leucine zippers at the end of intracellular tails ${ }^{81}, 3$ ) altering of TCR glycosylation ${ }^{82}$, and 4) substitution of particular TCR residues ${ }^{2}$. Extensive comparison has been performed between poorly and strongly expressed human TCRs and key residues have been identified, which affect the level of surface expression. Interestingly, these residues are outside the complementary determining regions of the variable domains and are therefore accessible to replacements without affecting $T$ cell specificity ${ }^{2}$.

\section{Endogenous TCR knock-down.}

The ability to suppress the endogenous TCR repertoire during the process of T cell engineering to redirect antigen specificity is also important to improve effectiveness of the introduced TCR and allow the safe use of third-party or allogeneic T cell donors ${ }^{83}$. Gene editing tools such as CRISPR-Cas9, TALENs and MegaTAL nucleases are all currently being evaluated for their ability to reliably and efficiently edit primary human $T$ cells, and recently published work has described a strategy to simultaneous knock down the endogenous TCR beta chain in recipient T cells using CRISPR/Cas9 while transducing a cancer-reactive TCR of choice ${ }^{84}$. This TCR replacement strategy resulted in markedly increased surface expression of both transgenic $\alpha \beta$ and $\gamma \delta$ TCRs, which in turn translated to a stronger, and more polyfunctional response of engineered T cells to their target cancer cell lines. Additionally, the TCR-plus-CRISPR-modified T cells were up to a thousand-fold more sensitive to antigen in vitro than standard TCR-transduced T cells or conventional model proxy systems used for 
studying TCR activity ${ }^{84}$. Additional strategies for endogenous TCR down-regulation include the use of small interfering RNA (siRNA) ${ }^{85}$ or designed zinc-finger nucleases ${ }^{86}$.

\section{Single-chain TCRs.}

As discussed above, a recognised complication of TCR gene therapy is the ability of introduced TCR $\alpha$ and $\beta$ chains to mismatch with endogenous $T$ cell receptors leading to undesirable, and potentially dangerous, reactivities. A novel approach to alleviate mispairing and accomplish safe adoptive immunotherapy for bulk endogenous TCR $\alpha / \beta$-positive $T$ cells has been demonstrated by recent reports using single-chain $\mathrm{TCRs}^{9}$. One group engineered a recombinant TCR consisting of a single-chain $\mathrm{V} \alpha-\mathrm{V} \beta-\mathrm{C} \beta$ and a $\mathrm{C} \alpha$ chain, which only paired with each other and not the endogenous $\mathrm{TCR}^{87}$. Other groups have used a stabilised $V \alpha-V \beta$ single-chain TCR linked to intracellular signalling domains to elicit functional activation of $T$ cells in the absence of co-receptors and to circumvent mispairing with endogenous TCRs ${ }^{88-90}$. Both approaches generated genetically modified TCRs with a more chimeric antigen receptor (CAR)-like structure, whilst allowing transduced cells to keep all the advantages of TCR recognition, including: 1) the ability of targeting antigens derived from the entire protein composition of tumour cells, including intracellular proteins, and also from a number of non-surface antigens of virally infected cells and tumours associated with viral infection; and 2) the capacity of targeting the whole cancer mutagenome, which is particularly important in the context of solid tumours. Although patient T cells are tolerant to peptides derived from self-proteins, point mutations in tumour cells resulting in single amino acid substitutions can elicit robust $\mathrm{T}$ cell responses. There are two mechanisms whereby point mutations can generate immunogenic epitopes to which patient $T$ cells are not tolerant ${ }^{91}$. First, mutations may generate novel TCR contact residues thereby producing immunogenic neoepitopes or, alternatively, they may create novel HLA-binding residues resulting in the presentation of peptides in tumour cells that are absent in normal tissues. Because of recognition of linear peptide sequences, TCRs can potentially target the mutational landscape associated with cancer development.

\section{Targeted gene delivery}

Apart from cell separation prior to transduction, methods of targeted gene delivery have been developed, which may facilitate the transduction of a specific subpopulation without the need for specific cell sorting procedures prior to genetic modification. It is the case of previously published work describing a lentiviral-derived vector delivering genes exclusively and specifically to $\mathrm{CD}^{+} \mathrm{T}$ cells ${ }^{92}$. This technology relies on engineered glycoproteins of measles virus (MV), which are the hemagglutinin $(\mathrm{H})$ and fusion $(\mathrm{F})$ proteins, both incorporated into the envelope membrane of lentiviral particles. Cell-type specificity is provided through a single-chain antibody (scFv) that recognizes a cellsurface antigen selectively expressed on the cell type of interest fused to an engineered $\mathrm{H}$ protein, 
which is blinded for its natural receptors CD46 (complement regulatory protein) and CD150 (signalling lymphocyte activation molecule, SLAM). The extension of this technology to other target cells of interest relies on the availability of suitable scFv. These must not only be specific for the target cell but also have to be efficiently expressed on the surface of the packaging cells as $\mathrm{H}$ protein fusion to become readily incorporated into vector particles ${ }^{92}$.

\section{Closed systems and automated platforms}

One of the main challenges in growing clinical grade cells for immunotherapy, particularly when large doses are required, is the development of a manufacturing process that is efficient, rigorous and reproducible. With this in mind, fully closed system platforms have been developed, which help standardise manufacturing procedures and reduce the risk of contamination.

An example of such a system is the CliniMACS Prodigy ${ }^{\circledR}$, which offers an automated all-in-one solution for cell processing and has been widely used for the production of CAR T cells ${ }^{93-95}$. Unfortunately, the current yield of this fully automated and closed system ranges from only $1-5 \times 10^{9}$ cells, which is sufficient to treat patients enrolled on most CAR T cell protocols for haematologic malignancies, but inadequate for many TCR T cell protocols, which may require up to $1 \times 10^{11}$ cells per adult patient. Although only partially closed, a large-scale manufacturing process using modular systems and semiautomated devices has been recently described, which resulted in highly functional clinical-grade TCRtransduced T cells ${ }^{52}$.

\section{Ongoing Challenges}

\section{Minimising toxicity}

As previously mentioned, toxicity constitutes one of the main concerns in TCR gene therapy. Immunotherapy using T cells with redirected specificities has historically favoured strategies leading to the production of cells with stable expression of the introduced TCR, which can then persist in the host and establish a memory-like T cell immunity. However, the expansion and long-term presence of antigen-specific T cells can also result in side-effects due to off-target activation of the introduced T cells and/or the massive uncontrolled lysis of targeted cells. Given the already discussed possibility of adverse events with the use of TCR-engineered T cells, it is beneficial to preserve the ability to eradicate all - and only - transferred cells, if needed. For this purpose, strategies exist to turn off antigen receptor expression or eliminate the engineered cells after transfer by incorporating certain "suicide genes" into the transgene (reviewed in ${ }^{96}$ ). A common approach incorporates caspase 9 under an inducible promoter (iC9) to initiate apoptosis of transduced cells ${ }^{97}$.

Additionally, new techniques are being developed that aim at promoting only transient expression of the genetically modified TCR to reduce toxicity. Indeed, a significant body of evidence is currently 
emerging showing that direct electroporation of mRNA encoding specific TCRs allows the production of large quantities of TCR-redirected T cells only transiently expressing the TCR ${ }^{98-101}$. Moreover, when used in conjunction with interference of endogenous TCR expression, these approaches have recently been described as leading to unprecedented levels of transgene TCR expression due to a strongly reduced degree of TCR mispairing ${ }^{101}$.

Although the functional efficiency of such cells is limited, the mRNA TCR-redirected T cells have been observed to possess anti-tumour activity ${ }^{98,102}$. Because these cells are not genetically modified in the sense that the there is, in fact, no permanent alteration of their genetic material, and because of their limited life span, they can be adoptively transferred in escalating doses and their potential toxicities more easily managed. However, further in vivo validation of these approaches is required before they can be safely used to engineer T cells for clinical trials.

\section{Counteracting the inhibitory tumour microenvironment}

By definition, tumour existence is dependent on the inhibition of endogenous immune control. This is achieved through a variety of mechanisms, including cell-cell signalling and release of soluble cytokines, all resulting in down-modulation of immune cell activity ${ }^{103}$. Importantly, like the endogenous immune system, adoptively transferred T cells are also susceptible to tumour-mediated immunosuppression ${ }^{104}$.

Current cancer immunotherapies focus on overcoming this inhibition, either by global activation of the immune system or by local manipulation of immunoregulatory molecules. These so-called immune checkpoint molecules transduce co-inhibitory signals to immune competent cells and are one of the most important components underlying the immunosuppressive capacity of the tumour microenvironment.

Cytotoxic T-lymphocyte-associated protein 4 (CTLA-4) and programmed cell death-1 (PD-1) are typical immune checkpoint molecules involved in the suppression of anti-tumour immunity. The first approved checkpoint inhibitor blocking therapy was Ipilimumab, an antibody that inhibits CTLA-4 ${ }^{104}$, followed by Nivolumab ${ }^{105,106}$ and Pembrolizumab (formerly known as Lambrolizumab) ${ }^{107}$, both targeting PD-1. Compared to traditional anti-cancer therapies, the use of these antibodies has been shown to provide superior clinical efficacies, including prolongation of overall survival and increase of objective response rates in some types of cancers, including melanoma, non-small cell lung cancer, renal carcinoma and urothelial bladder cancer (reviewed in ${ }^{108}$ ).

Administration of a PD-1 blocking antibody in conjunction with adoptive CAR T cell immunotherapy has also been shown to enhance CAR T cell therapy in preclinical models ${ }^{109}$, a finding that suggests that modifying $T$ cells to be intrinsically resistant to checkpoint inhibition could enhance engineered $T$ cell efficacy in humans. With this in mind, pre-clinical work is now being performed to engineer CAR T 
cells so that they are able to co-express factors boosting CAR-T cell function in the tumour microenvironment ${ }^{110}$.

Whilst incorporation of multiple forms of checkpoint blockade is also expected to be applicable to TCR-modified cells and, to some extent, improve their efficacy, it is important to keep in mind that resistance may be a significant obstacle in the application of such therapeutic strategies (see below).

\section{Target identification}

Systemically administered T cells have the potential of actively trafficking to nearly every site in the body ${ }^{111,112}$. The selection of the appropriate target is therefore important, as most potential targets are not tumour-specific, being expressed on healthy tissue at lower concentrations, therefore increasing the risk of "off-tumour/on-target" adverse effects (as discussed above). A wide variety of potential solid tumour targets are currently under consideration and being evaluated in clinical trials (Table 1). However, it is important to highlight that, even if highly expressed/specific tumour targets were to be identified, it is unlikely that they would be evenly expressed throughout the whole tumour due to intra-tumoural heterogeneity, meaning that $T$ cell therapy directed against a target that is not present on all tumour cells may run the risk of selecting for target-negative tumour outgrowth ${ }^{103}$. An important breakthrough for the identification of new cell targets is, therefore, the discovery of methods to target "neo-antigens" that are particular to each mutated tumour cell. Recent studies have shown that tumours from patients relapsing or not responding to checkpoint inhibitor therapy have mutations in genes encoding the IFN- $\gamma$ pathway ${ }^{113,114}$. These mutations affect the levels of MHCI on the cell surface, as cells are impaired to induce expression of the peptide transporter associated with antigen presentation (TAP) ${ }^{115}$. Due to this TAP deficiency, cells express very low levels of MHC-I, but also an alternative repertoire of self-antigens called TEIPP ( $T$ cell epitopes associated with impaired peptide processing). TEIPP are presented independently of TAP, and only appear in tumour cells with impaired antigen presentation machinery ${ }^{116}$.

Whilst TEIPP-specific T cells are, therefore, a potential candidate to treat immune-escaped, MHC-I low tumours ${ }^{117,118}$, they will only be able to target tumour cells with incomplete MHC-I ablation, as TEIPP antigen presentation is MHC-I-dependent.

\section{MHC-I downregulation}

To circumvent the need for the presence of MHC-I on tumour cells for recognition by tumour-specific T cells, artificial receptors such as CAR molecules can be used.

ACT using CAR-modified T cells holds the capacity of the same effector function as TCR-modified T cells, but independently of MHC-I expression ${ }^{119}$. However, whilst impressive clinical responses have already been seen in haematological malignancies with CD19-specific CAR T cells ${ }^{120}$, which has since led to the exploration of using CAR therapy in solid tumours (reviewed in ${ }^{121,122}$ ), TCR-modified T cells 
still feature a number of specific advantages that would prove beneficial in the context of cancer immunotherapy. As mentioned above, TCRs recognise processed peptides presented by MHC molecules, which means that they can target antigens from the entire protein composition of tumour cells. This is in contrast to CARs, whose potential targets are restricted to cell surface antigens expressed at higher densities on cancer cells ${ }^{11}$. Additionally, four to ten peptide-MHC molecules have been shown to be sufficient to elicit $T$ cell activation, whereas previously published studies investigating the density of $C D 20$ required to activate $T$ cells expressing a CD20-specific CAR showed that a minimum of 200 molecules/cell were required in order for cytokine release to be achieved ${ }^{123,124}$. The development of MHC-I recovery approaches for clinical use could be beneficial to enhance the therapeutic effects of TCR-modified T cells. Transfection of the tumour suppressor Fhit gene in MHCI-negative tumour cell lines has been shown to restore MHC-I cell surface expression ${ }^{125}$. Likewise, preclinical in vivo work has suggested that restoration of MHC-I expression by modulation of epigenetic markers, such as inhibitors of DNA methyltransferase (DNMT) or histone deacetylase (HDAC), constitutes an attractive approach to be used as a complement to TCR-modified T cell administration for successful tumour eradication ${ }^{126-128}$, even in the context of cancers that are resistant to immune checkpoint blockade ${ }^{129}$. A few clinical trials have been performed evaluating the effects of combining epigenetic modulation with vaccine/antibody/cytokine-based immunotherapy, which rendered promising results ${ }^{130-132}$. However, the feasibility/benefit of this approach in the context of clinical ACT using remains to be determined.

\section{Conclusion}

Rapid developments in research combined with impressive clinical results and recent FDA approvals for CAR T cells have facilitated the adoption of T cell engineering in the academic, clinical, and commercial sectors. Researchers now have the tools to deliver complex genetic modifications in order to optimise many aspects of $\mathrm{T}$ cell function. However, one of the most important challenges remains target antigen selection. TCRs for shared tumour-associated and lineage-specific antigens, which are capable of being stimulated by low concentrations of cognate antigen remain attractive therapeutics for the treatment of a wide range of malignancies.

\section{Acknowledgments}

Clinical trial NCT02988258 is supported by funding from the Medical Research Council and the NIHR UCLH/UCL Biomedical Research Centre. ECM is also supported by Bloodwise and CellMedica. 


\section{Conflict of Interest}

R.T.R and M.W.L.: no competing financial interests to disclose.

E.C.M.: CellMedica sponsored research collaboration and royalties; Kite/Gilead, GSK and Novartis advisory boards; GE consulting. 


\section{References}

1. Barrett, D. M., Grupp, S. A. \& June, C. H. Chimeric Antigen Receptor- and TCR-Modified T Cells Enter Main Street and Wall Street. J. Immunol. 195, 755-61 (2015).

2. Morris, E. C. \& Stauss, H. J. Optimizing T cell receptor gene therapy for hematologic malignancies. Blood 127, 3305-11 (2016).

3. Novartis. Novartis receives first ever FDA approval for a CAR-T cell therapy, Kymriah ${ }^{\mathrm{TM}}$ (tisagenlecleucel, CTL019), for children and young adults with B-cell ALL that is refractory or has relapsed at least twice [press release].

4. Gilead. Kite's Yescarta ${ }^{\mathrm{TM}}$ (Axicabtagene Ciloleucel) becomes first CAR T therapy approved by the FDA for the treatment of adult patients with relapsed or refractory large B-cell lymphoma after two or more lines of systemic therapy [press release].

5. Kuhns, M. S., Davis, M. M. \& Garcia, K. C. Deconstructing the Form and Function of the TCR/CD3 Complex. Immunity 24, 133-139 (2006).

6. Wucherpfennig, K. W., Gagnon, E., Call, M. J., Huseby, E. S. \& Call, M. E. Structural biology of the $\mathrm{T}$ cell receptor: insights into receptor assembly, ligand recognition, and initiation of signaling. Cold Spring Harb. Perspect. Biol. 2, a005140 (2010).

7. Chen, L. \& Flies, D. B. Molecular mechanisms of T cell co-stimulation and co-inhibition. Nat. Rev. Immunol. 13, 227-242 (2013).

8. Gaud, G., Lesourne, R. \& Love, P. E. Regulatory mechanisms in T cell receptor signalling. Nat. Rev. Immunol. 18, 485-497 (2018).

9. Spear, T. T., Nagato, K. \& Nishimura, M. I. Strategies to genetically engineer T cells for cancer immunotherapy. Cancer Immunol. Immunother. 65, 631-649 (2016).

10. Ye, B. et al. Genetically Modified T cell-Based Adoptive Immunotherapy in Hematological Malignancies. J. Immunol. Res. 2017, 5210459 (2017).

11. Harris, D. T. \& Kranz, D. M. Adoptive T Cell Therapies: A Comparison of T Cell Receptors and Chimeric Antigen Receptors. Trends Pharmacol. Sci. 37, 220-230 (2016).

12. Esensten, J. H., Helou, Y. A., Chopra, G., Weiss, A. \& Bluestone, J. A. CD28 Costimulation: From Mechanism to Therapy. Immunity 44, 973-988 (2016).

13. Purbhoo, M. A., Irvine, D. J., Huppa, J. B. \& Davis, M. M. T cell killing does not require the formation of a stable mature immunological synapse. Nat. Immunol. 5, 524-530 (2004).

14. Manz, B. N., Jackson, B. L., Petit, R. S., Dustin, M. L. \& Groves, J. T cell triggering thresholds are modulated by the number of antigen within individual T cell receptor clusters. Proc. Natl. Acad. Sci. U. S. A. 108, 9089-94 (2011).

15. Artyomov, M. N., Lis, M., Devadas, S., Davis, M. M. \& Chakraborty, A. K. CD4 and CD8 binding to MHC molecules primarily acts to enhance Lck delivery. Proc. Natl. Acad. Sci. U. S. A. 107, 
16916-21 (2010).

16. Gilham, D. E. et al. Adoptive T cell therapy for cancer in the United kingdom: a review of activity for the British Society of Gene and Cell Therapy annual meeting 2015. Hum. Gene Ther. 26, 276-85 (2015).

17. Karpanen, T. \& Olweus, J. T cell receptor gene therapy--ready to go viral? Mol. Oncol. 9, 201942 (2015).

18. Ikeda, H. T cell adoptive immunotherapy using tumor-infiltrating T cells and genetically engineered TCR-T cells: Table 1. Int. Immunol. 28, 349-353 (2016).

19. Duong, C. P. M., Yong, C. S. M., Kershaw, M. H., Slaney, C. Y. \& Darcy, P. K. Cancer immunotherapy utilizing gene-modified T cells: From the bench to the clinic. Mol. Immunol. 67, 46-57 (2015).

20. Schub, A., Schuster, I. G., Hammerschmidt, W. \& Moosmann, A. CMV-specific TCR-transgenic T cells for immunotherapy. J. Immunol. 183, 6819-30 (2009).

21. Kah, J. et al. Lymphocytes transiently expressing virus-specific T cell receptors reduce hepatitis B virus infection. J. Clin. Invest. 127, 3177-3188 (2017).

22. Banu, N. et al. Building and optimizing a virus-specific $T$ cell receptor library for targeted immunotherapy in viral infections. Sci. Rep. 4, 4166 (2014).

23. Joseph, A. et al. Lentiviral Vectors Encoding Human Immunodeficiency Virus Type 1 (HIV-1)Specific T cell Receptor Genes Efficiently Convert Peripheral Blood CD8 T Lymphocytes into Cytotoxic T Lymphocytes with Potent In Vitro and In Vivo HIV-1-Specific Inhibitory Activity. J. Virol. 82, 3078-3089 (2008).

24. Morgan, R. A. et al. Cancer Regression in Patients After Transfer of Genetically Engineered Lymphocytes. Science. 314, 126-129 (2006).

25. Duval, L. et al. Adoptive transfer of allogeneic cytotoxic T lymphocytes equipped with a HLAA2 restricted MART-1 T cell receptor: a phase I trial in metastatic melanoma. Clin. Cancer Res. $12,1229-36$ (2006)

26. Johnson, L. A. et al. Gene therapy with human and mouse T cell receptors mediates cancer regression and targets normal tissues expressing cognate antigen. Blood 114, 535-546 (2009).

27. van den Berg, J. H. et al. Case Report of a Fatal Serious Adverse Event Upon Administration of T Cells Transduced With a MART-1-specific T cell Receptor. Mol. Ther. 23, 1541-50 (2015).

28. Morgan, R. A. et al. High efficiency TCR gene transfer into primary human lymphocytes affords avid recognition of melanoma tumor antigen glycoprotein 100 and does not alter the recognition of autologous melanoma antigens. J. Immunol. 171, 3287-95 (2003).

29. Kuball, J. et al. Cooperation of human tumor-reactive CD4+ and CD8+ T cells after redirection of their specificity by a high-affinity p53A2.1-specific TCR. Immunity 22, 117-29 (2005).

30. Rapoport, A. P. et al. NY-ESO-1-specific TCR-engineered T cells mediate sustained antigen- 
specific antitumor effects in myeloma. Nat. Med. 21, 914-921 (2015).

31. Park, J., Zhong, S., Krogsgaard, M. \& Mazumder, A. MAGE-A3 Specific T cell Receptor Adoptive Cell Transfer of Multiple Myeloma. Blood 120, (2012).

32. Kageyama, S. et al. Adoptive Transfer of MAGE-A4 T cell Receptor Gene-Transduced Lymphocytes in Patients with Recurrent Esophageal Cancer. Clin. Cancer Res. 21, 2268-2277 (2015).

33. Border, E. et al. Abstract 2564: Selection of affinity-enhanced T cell receptors for adoptive T cell therapy targeting MAGE-A10. Cancer Res. 78, 2564-2564 (2018).

34. Draper, L. M. et al. Targeting of HPV-16+ Epithelial Cancer Cells by TCR Gene Engineered T Cells Directed against E6. Clin. Cancer Res. 21, 4431-4439 (2015).

35. Jin, B. Y. et al. Engineered T cells targeting E7 mediate regression of human papillomavirus cancers in a murine model. JCl insight 3, (2018).

36. Stone, J. D., Harris, D. T. \& Kranz, D. M. TCR affinity for p/MHC formed by tumor antigens that are self-proteins: impact on efficacy and toxicity. Curr. Opin. Immunol. 33, 16-22 (2015).

37. Linette, G. P. et al. Cardiovascular toxicity and titin cross-reactivity of affinity-enhanced T cells in myeloma and melanoma. Blood 122, 863-71 (2013).

38. Leen, A. M. et al. Multicenter study of banked third-party virus-specific T cells to treat severe viral infections after hematopoietic stem cell transplantation. Blood 121, 5113-23 (2013).

39. Stemberger, C. et al. Lowest numbers of primary CD8(+) T cells can reconstitute protective immunity upon adoptive immunotherapy. Blood 124, 628-37 (2014).

40. Peggs, K. S. et al. Adoptive cellular therapy for early cytomegalovirus infection after allogeneic stem-cell transplantation with virus-specific T cell lines. Lancet 362, 1375-1377 (2003).

41. Thimme, R. et al. CD8(+) T cells mediate viral clearance and disease pathogenesis during acute hepatitis B virus infection. J. Virol. 77, 68-76 (2003).

42. Viganò, S. et al. HLA-G+ HIV-1-specific CD8+ T cells are associated with HIV-1 immune control. AIDS 31, 207-212 (2017).

43. Mueller, K. et al. Protective capacity of virus-specific T cell receptor-transduced CD8 T cells in vivo. J. Virol. 86, 10866-9 (2012).

44. Joseph, A. et al. Lentiviral vectors encoding human immunodeficiency virus type 1 (HIV-1)specific T cell receptor genes efficiently convert peripheral blood CD8 T lymphocytes into cytotoxic T lymphocytes with potent in vitro and in vivo HIV-1-specific inhibitory activity. J. Virol. 82, 3078-89 (2008).

45. Leibman, R. S. \& Riley, J. L. Engineering T Cells to Functionally Cure HIV-1 Infection. Mol. Ther. 23, 1149-1159 (2015).

46. Parkin, D. M. The global health burden of infection-associated cancers in the year 2002. Int. J. cancer 118, 3030-44 (2006). 
47. Qasim, W. et al. Immunotherapy of HCC metastases with autologous T cell receptor redirected T cells, targeting HBsAg in a liver transplant patient. J. Hepatol. 62, 486-91 (2015).

48. McClary, H., Koch, R., Chisari, F. V \& Guidotti, L. G. Relative sensitivity of hepatitis B virus and other hepatotropic viruses to the antiviral effects of cytokines. J. Virol. 74, 2255-64 (2000).

49. Guidotti, L. G. et al. Intracellular inactivation of the hepatitis B virus by cytotoxic T lymphocytes. Immunity 4, 25-36 (1996).

50. Rohaan, M. W., Wilgenhof, S. \& Haanen, J. B. A. G. Adoptive cellular therapies: the current landscape. Virchows Arch. (2018). doi:10.1007/s00428-018-2484-0

51. Linnemann, C., Schumacher, T. N. M. \& Bendle, G. M. T cell receptor gene therapy: critical parameters for clinical success. J. Invest. Dermatol. 131, 1806-16 (2011).

52. Jin, J. et al. Enhanced clinical-scale manufacturing of TCR transduced T cells using closed culture system modules. J. Transl. Med. 16, 13 (2018).

53. Grupp, S. A. et al. Chimeric Antigen Receptor-Modified T Cells for Acute Lymphoid Leukemia. N. Engl. J. Med. 368, 1509-1518 (2013).

54. Cameron, B. J. et al. Identification of a Titin-derived HLA-A1-presented peptide as a crossreactive target for engineered MAGE A3-directed T cells. Sci. Transl. Med. 5, 197 ra103 (2013).

55. Johnson, L. A. et al. Gene therapy with human and mouse T cell receptors mediates cancer regression and targets normal tissues expressing cognate antigen. Blood 114, 535-546 (2009).

56. Manning, T. C., Parke, E. A., Teyton, L. \& Kranz, D. M. Effects of complementarity determining region mutations on the affinity of an alpha/beta $T$ cell receptor: measuring the energy associated with CD4/CD8 repertoire skewing. J. Exp. Med. 189, 461-70 (1999).

57. Robbins, P. F. et al. Single and dual amino acid substitutions in TCR CDRs can enhance antigenspecific T cell functions. J. Immunol. 180, 6116-31 (2008).

58. Wooldridge, L. et al. A single autoimmune $T$ cell receptor recognizes more than a million different peptides. J. Biol. Chem. 287, 1168-77 (2012).

59. Thomas, S., Stauss, H. J. \& Morris, E. C. Molecular immunology lessons from therapeutic T cell receptor gene transfer. Immunology 129, 170-177 (2010).

60. Wang, X. \& Rivière, I. Manufacture of tumor- and virus-specific T lymphocytes for adoptive cell therapies. Cancer Gene Ther. 22, 85-94 (2015).

61. Hildinger, M., Abel, K. L., Ostertag, W. \& Baum, C. Design of 5' untranslated sequences in retroviral vectors developed for medical use. J. Virol. 73, 4083-9 (1999).

62. Kuball, J. et al. Facilitating matched pairing and expression of TCR chains introduced into human T cells. Blood 109, 2331-8 (2007).

63. Sommermeyer, D. \& Uckert, W. Minimal amino acid exchange in human TCR constant regions fosters improved function of TCR gene-modified T cells. J. Immunol. 184, 6223-31 (2010).

64. Cohen, C. J., Zhao, Y., Zheng, Z., Rosenberg, S. A. \& Morgan, R. A. Enhanced antitumor activity 
of murine-human hybrid T cell receptor (TCR) in human lymphocytes is associated with improved pairing and TCR/CD3 stability. Cancer Res. 66, 8878-86 (2006).

65. Hart, D. P. et al. Retroviral transfer of a dominant TCR prevents surface expression of a large proportion of the endogenous TCR repertoire in human T cells. Gene Ther. 15, 625-31 (2008).

66. Thomas, S. et al. Targeting the Wilms tumor antigen 1 by TCR gene transfer: TCR variants improve tetramer binding but not the function of gene modified human T cells. J. Immunol. 179, 5803-10 (2007).

67. European Medicines Agency (EMA). Note for guidance on specifications: test procedures and acceptance criteria for biotechnological/biological products (ICH Topic Q6B, CPMP/ICH/365/96) (effective from 01/09/1999).

68. Bravery, C. A. et al. Potency assay development for cellular therapy products: an ISCT review of the requirements and experiences in the industry. Cytotherapy 15, 9-19.e9 (2013).

69. European Medicines Agency (EMA). Guideline on human cell-based medicinal products (CHMP/410869/2006) (effective from 01/09/2008).

70. European Medicines Agency (EMA). Guideline on potency testing of cell based immunotherapy medicinal products for the treatment of cancer (CHMP/BWP/271475/2006 Rev.1) (effective from 01/09/2016).

71. Guideline on quality, non-clinical and clinical aspects of medicinal products containing genetically modified cells (CHMP/GTWP/671639/2008) (effective from 01/11/2012).

72. Biffi, A. et al. Lentiviral hematopoietic stem cell gene therapy benefits metachromatic leukodystrophy. Science 341, 1233158 (2013).

73. Aiuti, A. et al. Lentiviral Hematopoietic Stem Cell Gene Therapy in Patients with Wiskott-Aldrich Syndrome. Science. 341, 1233151-1233151 (2013).

74. Cavazzana-Calvo, M. et al. Transfusion independence and HMGA2 activation after gene therapy of human $\beta$-thalassaemia. Nature 467, 318-22 (2010).

75. Cartier, N. et al. Hematopoietic Stem Cell Gene Therapy with a Lentiviral Vector in X-Linked Adrenoleukodystrophy. Science. 326, 818-823 (2009).

76. Morris, E. C. et al. Gene therapy for Wiskott-Aldrich syndrome in a severely affected adult. Blood 130, 1327-1335 (2017).

77. Hacein-Bey-Abina, S. et al. A Modified Y-Retrovirus Vector for X-Linked Severe Combined Immunodeficiency. N. Engl. J. Med. 371, 1407-1417 (2014).

78. Huls, M. H. et al. Clinical application of Sleeping Beauty and artificial antigen presenting cells to genetically modify $\mathrm{T}$ cells from peripheral and umbilical cord blood. J. Vis. Exp. e50070 (2013). doi:10.3791/50070

79. Singh, H. et al. Manufacture of clinical-grade CD19-specific T cells stably expressing chimeric antigen receptor using Sleeping Beauty system and artificial antigen presenting cells. PLoS One 
8, e64138 (2013).

80. Ahmadi, M. et al. CD3 limits the efficacy of TCR gene therapy in vivo. Blood 118, 3528-3537 (2011).

81. Chang, H. C. et al. A general method for facilitating heterodimeric pairing between two proteins: application to expression of alpha and beta T cell receptor extracellular segments. Proc. Natl. Acad. Sci. U. S. A. 91, 11408-12 (1994).

82. Kuball, J. et al. Increasing functional avidity of TCR-redirected T cells by removing defined Nglycosylation sites in the TCR constant domain. J. Exp. Med. 206, 463-75 (2009).

83. Morris, E. C. Editing gene engineering to enhance function. Blood 131, 272-273 (2018).

84. Legut, M., Dolton, G., Mian, A. A., Ottmann, O. G. \& Sewell, A. K. CRISPR-mediated TCR replacement generates superior anticancer transgenic T cells. Blood 131, 311-322 (2018).

85. Okamoto, S. et al. Improved expression and reactivity of transduced tumor-specific TCRs in human lymphocytes by specific silencing of endogenous TCR. Cancer Res. 69, 9003-11 (2009).

86. Provasi, E. et al. Editing T cell specificity towards leukemia by zinc finger nucleases and lentiviral gene transfer. Nat. Med. 18, 807-815 (2012).

87. Voss, R.-H. et al. Coexpression of the $T$ cell receptor constant alpha domain triggers tumor reactivity of single-chain TCR-transduced human T cells. Blood 115, 5154-63 (2010).

88. Knies, D. et al. An optimized single chain TCR scaffold relying on the assembly with the native CD3-complex prevents residual mispairing with endogenous TCRs in human T cells. Oncotarget 7, 21199-221 (2016).

89. Stone, J. D. et al. A novel T cell receptor single-chain signaling complex mediates antigenspecific T cell activity and tumor control. Cancer Immunol. Immunother. 63, 1163-76 (2014).

90. Aggen, D. H. et al. Single-chain $\operatorname{VaV\beta } \mathrm{T}$ cell receptors function without mispairing with endogenous TCR chains. Gene Ther. 19, 365-74 (2012).

91. Morris, E. C. \& Stauss, H. J. Optimizing T cell receptor gene therapy for hematologic malignancies. Blood 127, 3305-11 (2016).

92. Zhou, Q. et al. T cell receptor gene transfer exclusively to human CD8(+) cells enhances tumor cell killing. Blood 120, 4334-42 (2012).

93. Zhu, F. et al. Closed-system manufacturing of CD19 and dual-targeted CD20/19 chimeric antigen receptor T cells using the CliniMACS Prodigy device at an academic medical center. Cytotherapy 20, 394-406 (2018).

94. Lock, D. et al. Automated Manufacturing of Potent CD20-Directed Chimeric Antigen Receptor T Cells for Clinical Use. Hum. Gene Ther. 28, 914-925 (2017).

95. Mock, U. et al. Automated manufacturing of chimeric antigen receptor T cells for adoptive immunotherapy using CliniMACS Prodigy. Cytotherapy 18, 1002-1011 (2016).

96. Jones, B. S., Lamb, L. S., Goldman, F. \& Di Stasi, A. Improving the safety of cell therapy products 
by suicide gene transfer. Front. Pharmacol. 5, 254 (2014).

97. Di Stasi, A. et al. Inducible Apoptosis as a Safety Switch for Adoptive Cell Therapy. N. Engl. J. Med. 365, 1673-1683 (2011).

98. Koh, S. et al. A practical approach to immunotherapy of hepatocellular carcinoma using $T$ cells redirected against hepatitis B virus. Mol. Ther. Nucleic Acids 2, e114 (2013).

99. Dörrie, J. et al. Human adenovirus-specific $\gamma / \delta$ and CD8+ $T$ cells generated by $T$ cell receptor transfection to treat adenovirus infection after allogeneic stem cell transplantation. PLoS One 9, e109944 (2014).

100. Balasiddaiah, A. et al. Hepatitis C Virus-Specific T Cell Receptor mRNA-Engineered Human T Cells: Impact of Antigen Specificity on Functional Properties. J. Virol. 91, (2017).

101. Campillo-Davo, D. et al. Efficient and Non-genotoxic RNA-Based Engineering of Human T Cells Using Tumor-Specific T Cell Receptors With Minimal TCR Mispairing. Front. Immunol. 9, 2503 (2018).

102. Kah, J. et al. Lymphocytes transiently expressing virus-specific T cell receptors reduce hepatitis B virus infection. J. Clin. Invest. 127, 3177-3188 (2017).

103. Fesnak, A. D., June, C. H. \& Levine, B. L. Engineered T cells: the promise and challenges of cancer immunotherapy. Nat. Rev. Cancer 16, 566-81 (2016).

104. Beatty, G. L. \& Moon, E. K. Chimeric antigen receptor T cells are vulnerable to immunosuppressive mechanisms present within the tumor microenvironment. Oncoimmunology 3, e970027 (2014).

105. Topalian, S. L. et al. Survival, durable tumor remission, and long-term safety in patients with advanced melanoma receiving nivolumab. J. Clin. Oncol. 32, 1020-30 (2014).

106. Topalian, S. L. et al. Safety, Activity, and Immune Correlates of Anti-PD-1 Antibody in Cancer. N. Engl. J. Med. 366, 2443-2454 (2012).

107. Hamid, O. et al. Safety and Tumor Responses with Lambrolizumab (Anti-PD-1) in Melanoma. N. Engl. J. Med. 369, 134-144 (2013).

108. Adachi, K. \& Tamada, K. Immune checkpoint blockade opens an avenue of cancer immunotherapy with a potent clinical efficacy. Cancer Sci. 106, 945-50 (2015).

109. John, L. B. et al. Anti-PD-1 antibody therapy potently enhances the eradication of established tumors by gene-modified T cells. Clin. Cancer Res. 19, 5636-46 (2013).

110. Rafiq, S. et al. Targeted delivery of a PD-1-blocking scFv by CAR-T cells enhances anti-tumor efficacy in vivo. Nat. Biotechnol. 36, 847-856 (2018).

111. Palmer, D. C. et al. Vaccine-stimulated, adoptively transferred CD8+ T cells traffic indiscriminately and ubiquitously while mediating specific tumor destruction. J. Immunol. 173, 7209-16 (2004).

112. Miao, H. et al. EGFRvIll-specific chimeric antigen receptor T cells migrate to and kill tumor 
deposits infiltrating the brain parenchyma in an invasive xenograft model of glioblastoma. PLoS One 9, e94281 (2014).

113. Gao, J. et al. Loss of IFN- $\gamma$ Pathway Genes in Tumor Cells as a Mechanism of Resistance to AntiCTLA-4 Therapy. Cell 167, 397-404.e9 (2016).

114. Zaretsky, J. M. et al. Mutations Associated with Acquired Resistance to PD-1 Blockade in Melanoma. N. Engl. J. Med. 375, 819-29 (2016).

115. Johnsen, A. K., Templeton, D. J., Sy, M. \& Harding, C. V. Deficiency of transporter for antigen presentation (TAP) in tumor cells allows evasion of immune surveillance and increases tumorigenesis. J. Immunol. 163, 4224-31 (1999).

116. van Hall, T. et al. Selective cytotoxic T-lymphocyte targeting of tumor immune escape variants. Nat. Med. 12, 417-24 (2006).

117. Doorduijn, E. M. et al. TAP-independent self-peptides enhance T cell recognition of immuneescaped tumors. J. Clin. Invest. 126, 784-94 (2016).

118. Doorduijn, E. M. et al. T cells specific for a TAP-independent self-peptide remain naïve in tumorbearing mice and are fully exploitable for therapy. Oncoimmunology 7, e1382793 (2018).

119. Gross, G., Waks, T. \& Eshhar, Z. Expression of immunoglobulin-T cell receptor chimeric molecules as functional receptors with antibody-type specificity. Proc. Natl. Acad. Sci. U. S. A. 86, 10024-8 (1989).

120. Maude, S. L., Shpall, E. J. \& Grupp, S. A. Chimeric antigen receptor T cell therapy for ALL. Hematol. Am. Soc. Hematol. Educ. Progr. 2014, 559-64 (2014).

121. Rohaan, M. W., Wilgenhof, S. \& Haanen, J. B. A. G. Adoptive cellular therapies: the current landscape. Virchows Arch. (2018). doi:10.1007/s00428-018-2484-0

122. June, C. H., O'Connor, R. S., Kawalekar, O. U., Ghassemi, S. \& Milone, M. C. CAR T cell immunotherapy for human cancer. Science 359, 1361-1365 (2018).

123. Stone, J. D., Aggen, D. H., Schietinger, A., Schreiber, H. \& Kranz, D. M. A sensitivity scale for targeting T cells with chimeric antigen receptors (CARs) and bispecific T cell Engagers (BiTEs). Oncoimmunology 1, 863-873 (2012).

124. Watanabe, K. et al. Target antigen density governs the efficacy of anti-CD20-CD28-CD3 $\zeta$ chimeric antigen receptor-modified effector CD8+ T cells. J. Immunol. 194, 911-20 (2015).

125. Romero, I. et al. The tumour suppressor Fhit positively regulates MHC class I expression on cancer cells. J. Pathol. 227, 367-79 (2012).

126. Park, J., Thomas, S. \& Munster, P. N. Epigenetic modulation with histone deacetylase inhibitors in combination with immunotherapy. Epigenomics 7, 641-652 (2015).

127. Símová, J. et al. Immunotherapy augments the effect of 5-azacytidine on HPV16-associated tumours with different MHC class I-expression status. Br. J. Cancer 105, 1533-41 (2011).

128. Garrido, F., Aptsiauri, N., Doorduijn, E. M., Garcia Lora, A. M. \& van Hall, T. The urgent need to 
recover MHC class I in cancers for effective immunotherapy. Curr. Opin. Immunol. 39, 44-51 (2016).

129. Kim, K. et al. Eradication of metastatic mouse cancers resistant to immune checkpoint blockade by suppression of myeloid-derived cells. Proc. Natl. Acad. Sci. U. S. A. 111, 11774-9 (2014).

130. Pili, R. et al. Immunomodulation by Entinostat in Renal Cell Carcinoma Patients Receiving HighDose Interleukin 2: A Multicenter, Single-Arm, Phase I/II Trial (NCI-CTEP\#7870). Clin. Cancer Res. 23, 7199-7208 (2017).

131. Hasanali, Z. S. et al. Epigenetic therapy overcomes treatment resistance in $\mathrm{T}$ cell prolymphocytic leukemia. Sci. Transl. Med. 7, 293ra102-293ra102 (2015).

132. Odunsi, K. et al. Epigenetic Potentiation of NY-ESO-1 Vaccine Therapy in Human Ovarian Cancer. Cancer Immunol. Res. 2, 37-49 (2014).

133. Yao, X. et al. Levels of peripheral $\mathrm{CD} 4(+) \mathrm{FoxP3}(+)$ regulatory $\mathrm{T}$ cells are negatively associated with clinical response to adoptive immunotherapy of human cancer. Blood 119, 5688-96 (2012).

134. Morgan, R. A. et al. Cancer Regression and Neurological Toxicity Following Anti-MAGE-A3 TCR Gene Therapy. J. Immunother. 36, 133-151 (2013).

135. Moore, T. et al. Clinical and immunologic evaluation of three metastatic melanoma patients treated with autologous melanoma-reactive TCR-transduced T cells. Cancer Immunol. Immunother. 67, 311-325 (2018). 
Table 1. Overview of past and present modified TCR gene therapy clinical trials (ClinicalTrials.gov).

\begin{tabular}{|c|c|c|c|c|c|c|c|}
\hline Antigen & Condition/disease & MHC restriction & Status & ClinicalTrials.gov ID & Outcomes $^{*}$ & Adverse Events & Reference $^{*}$ \\
\hline E7 & HPV-associated cancers & HLA-A*0201 & Recruiting & NCT02858310 & $N / A$ & N/A & $\mathrm{N} / \mathrm{A}$ \\
\hline Gag & HIV & HLA-A2 & Completed & NCT00991224 & $\mathrm{N} / \mathrm{A}$ & $\mathrm{N} / \mathrm{A}$ & $N / A$ \\
\hline gp100 & Metastatic melanoma & HLA-A*0201 & Terminated & NCT00509496 & $\begin{array}{l}\text { CR 1/21 } \\
\text { PR 3/21 }\end{array}$ & $\begin{array}{l}\text { SAE } 5 / 21 \\
\text { Hypotension, infections/infestations, } \\
\text { creatinine imbalances, somnolence/ } \\
\text { depressed level of consciousness, renal } \\
\text { failure, dyspnea, pneumonitis/pulmonary } \\
\text { infiltrates, acute vascular leak syndrome, } \\
\text { thrombosis/ thrombus/embolism }\end{array}$ & 133 \\
\hline AFP & Hepatocellular carcinoma & HLA-A*0201 & Recruiting & NCT03132792 & $N / A$ & $\mathrm{~N} / \mathrm{A}$ & $\mathrm{N} / \mathrm{A}$ \\
\hline HERV-E & Metastatic renal cell carcinoma & HLA-A*1101 & Recruiting & NCT03354390 & $\mathrm{N} / \mathrm{A}$ & $\mathrm{N} / \mathrm{A}$ & $N / A$ \\
\hline HPV E6 & HPV-associated cancers & HLA-A*0201 & Terminated & NCT02280811 & \multicolumn{3}{|c|}{$\begin{array}{l}\text { Diarrhea, infections/infestations, febrile } \\
\text { neutropenia, dyspnea, haemorrhage, } \\
\text { pulmonary/upper respiratory } \\
\text { (Bronchopulmonary NOS), hypoxia, } \\
\text { obstruction/stenosis of airway (bronchus), } \\
\text { prolonged intubation after pulmonary } \\
\text { resection (>24hrs after surgery) }\end{array}$} \\
\hline KRAS G12V & Metastatic/unresectable cancer & HLA-A*1101 & Recruiting & NCT03190941 & $N / A$ & N/A & $N / A$ \\
\hline MAGE-A3 & Metastatic cancer & $\mathrm{HLA}-\mathrm{A}^{\star} 01$ & Terminated & NCT02153905 & $\mathrm{N} / \mathrm{A}$ & $\mathrm{N} / \mathrm{A}$ & $\mathrm{N} / \mathrm{A}$ \\
\hline MAGE-A3-DP4 & Metastatic cancer & HLA-DP0401/0402 & Recruiting & NCT02111850 & $N / A$ & $\mathrm{~N} / \mathrm{A}$ & $N / A$ \\
\hline MAGE-A3/12 & Metastatic cancer & HLA-A*0201 & Terminated & NCT01273181 & $\begin{array}{l}\text { CR } 1 / 9 \\
\text { PR } 3 / 9\end{array}$ & $\begin{array}{c}\text { SAE 6/9 } \\
\text { Haemoglobin disorders, left ventricular } \\
\text { diastolic dysfunction, hypotension, } \\
\text { anorexia, nausea, fever, metabolism and } \\
\text { nutrition disorders, somnolence/depressed } \\
\text { level of consciousness, seizure, speech } \\
\text { impairment, renal failure, dyspnea, } \\
\text { hypoxia } \\
2 \text { fatalities }\end{array}$ & 134 \\
\hline MAGE-A4 & Solid tumours & HLA-A*24:02 & Recruiting & NCT02096614 & $\mathrm{N} / \mathrm{A}$ & $\mathrm{N} / \mathrm{A}$ & $\mathrm{N} / \mathrm{A}$ \\
\hline & Metastatic melanoma & HLA-A*0201 & $\begin{array}{c}\text { Active, } \\
\text { not recruiting }\end{array}$ & NCT02654821 & $N / A$ & $\mathrm{~N} / \mathrm{A}$ & $N / A$ \\
\hline
\end{tabular}




\begin{tabular}{|c|c|c|c|c|c|c|c|}
\hline Antigen & Condition/disease & MHC restriction & Status & ClinicalTrials.gov ID & Outcomes $^{*}$ & Adverse Events & Reference $^{\neq \neq}$ \\
\hline \multirow[b]{3}{*}{ MART-1 } & Advanced melanoma & HLA-A*0201 & Recruiting & NCT00910650 & $\mathrm{N} / \mathrm{A}$ & N/A & $\mathrm{N} / \mathrm{A}$ \\
\hline & & & & & & SAE $4 / 24$ & \\
\hline & Metastatic melanoma & HLA-A*0201 & Completed & NCT00509288 & PR 6/24 & $\begin{array}{c}\text { Infections/infestations, creatinine } \\
\text { disorders, somnolence/depressed level of } \\
\text { consciousness, renal failure, } \\
\text { rash/desquamation, } \\
\text { thrombosis/thrombus/embolism }\end{array}$ & $\mathrm{N} / \mathrm{A}$ \\
\hline \multirow{3}{*}{$\begin{array}{l}\text { MART-1 } \\
\text { (cont.) }\end{array}$} & Melanoma & HLA-A*0201 & Terminated & NCT00706992 & $\begin{array}{l}\text { No responses } \\
\text { observed }(n=40)\end{array}$ & Not reported & $\mathrm{N} / \mathrm{A}$ \\
\hline & Advanced melanoma & HLA-A*0201 & Terminated & NCT00612222 & $\begin{array}{l}\mathrm{N} / \mathrm{A} \\
\text { (study terminated) }\end{array}$ & $\begin{array}{c}\text { SAE } 1 / 4 \\
\text { Abnormal hearing test, uveitis, dizziness }\end{array}$ & $\mathrm{N} / \mathrm{A}$ \\
\hline & Metastatic melanoma & HLA-A*0201 & Completed & NCT00923195 & $\begin{array}{l}\text { No responses } \\
\text { observed }(n=4)\end{array}$ & $\begin{array}{c}\text { SAE } 3 / 4 \\
\text { Somnolence/depressed level of } \\
\text { consciousness, ischemia cerebrovascular, } \\
\text { seizure, renal failure }\end{array}$ & $\mathrm{N} / \mathrm{A}$ \\
\hline \multirow{11}{*}{ NY-ESO-1 } & Melanoma & HLA-A*0201 & Terminated & NCT02062359 & $\begin{array}{l}\text { No responses } \\
\text { observed }(n=2)\end{array}$ & SAE 0/2 & $\mathrm{N} / \mathrm{A}$ \\
\hline & Metastatic cancer & HLA-A*0201 & Terminated & NCT00670748 & $\begin{array}{l}\text { CR } 5 / 45 \\
\text { PR } 17 / 45\end{array}$ & $\begin{array}{c}\text { SAE } 8 / 45 \\
\text { Nausea, colitis, infection, hypoxia, } \\
\text { thrombosis/thrombus/embolism } \\
1 \text { fatality }\end{array}$ & $\mathrm{N} / \mathrm{A}$ \\
\hline & Solid tumours & HLA-A*0201/0206 & $\begin{array}{c}\text { Active, } \\
\text { not recruiting }\end{array}$ & NCT02366546 & $\mathrm{N} / \mathrm{A}$ & $\mathrm{N} / \mathrm{A}$ & $\mathrm{N} / \mathrm{A}$ \\
\hline & Ovarian cancer & $\begin{array}{c}\text { HLA- } \\
A^{*} 0201 / 0205 / 0206\end{array}$ & $\begin{array}{l}\text { Active, } \\
\text { not recruiting }\end{array}$ & NCT01567891 & $\mathrm{N} / \mathrm{A}$ & $\mathrm{N} / \mathrm{A}$ & $\mathrm{N} / \mathrm{A}$ \\
\hline & Metastatic cancer & HLA-A*0201 & Recruiting & NCT03240861 & $\mathrm{N} / \mathrm{A}$ & N/A & $\mathrm{N} / \mathrm{A}$ \\
\hline & $\begin{array}{l}\text { Solid tumour cancers and } \\
\text { melanoma }\end{array}$ & HLA-A*0201 & Recruiting & NCT01967823 & $\mathrm{N} / \mathrm{A}$ & $\mathrm{N} / \mathrm{A}$ & $\mathrm{N} / \mathrm{A}$ \\
\hline & Multiple myeloma & HLA-A*0201 & $\begin{array}{c}\text { Active, } \\
\text { not recruiting }\end{array}$ & NCT01352286 & $\mathrm{N} / \mathrm{A}$ & $\mathrm{N} / \mathrm{A}$ & $\mathrm{N} / \mathrm{A}$ \\
\hline & Solid tumours & HLA-A*0201 & Recruiting & NCT02070406 & $\mathrm{N} / \mathrm{A}$ & N/A & $\mathrm{N} / \mathrm{A}$ \\
\hline & Synovial sarcoma & HLA-A*0201/0206 & Recruiting & NCT03250325 & $\mathrm{N} / \mathrm{A}$ & N/A & $\mathrm{N} / \mathrm{A}$ \\
\hline & Solid tumours & HLA-A*0201 & Recruiting & NCT02775292 & $\mathrm{N} / \mathrm{A}$ & N/A & $\mathrm{N} / \mathrm{A}$ \\
\hline & Advanced malignancies & HLA-A*0201 & Recruiting & NCT01697527 & $\mathrm{N} / \mathrm{A}$ & $\mathrm{N} / \mathrm{A}$ & $N / A$ \\
\hline
\end{tabular}




\begin{tabular}{|c|c|c|c|c|c|c|c|}
\hline Antigen & Condition/disease & MHC restriction & Status & ClinicalTrials.gov ID & Outcomes ${ }^{*}$ & Adverse Events & Reference $¥ \neq$ \\
\hline \multirow{4}{*}{$\begin{array}{l}\text { NY-ESO-1 } \\
\text { (cont.) }\end{array}$} & Metastatic cancer & HLA-A*0201 & Recruiting & NCT02774291 & $\mathrm{N} / \mathrm{A}$ & $\mathrm{N} / \mathrm{A}$ & $\mathrm{N} / \mathrm{A}$ \\
\hline & Solid tumours & HLA-A*0201 & Recruiting & NCT02650986 & $\mathrm{N} / \mathrm{A}$ & $\mathrm{N} / \mathrm{A}$ & $\mathrm{N} / \mathrm{A}$ \\
\hline & Solid tumours & HLA-A*0201/0206 & Recruiting & NCT02869217 & $\mathrm{N} / \mathrm{A}$ & $\mathrm{N} / \mathrm{A}$ & $N / A$ \\
\hline & Various malignancies & HLA-A2 & Recruiting & NCT02457650 & $N / A$ & $N / A$ & $N / A$ \\
\hline \multirow{2}{*}{ p53 } & Metastatic cancer & HLA-A*0201 & Terminated & NCT00704938 & $\begin{array}{c}\text { Not reported } \\
(\mathrm{n}=3)\end{array}$ & SAE $0 / 3$ & $\mathrm{~N} / \mathrm{A}$ \\
\hline & Metastatic cancer & HLA-A*0201 & Completed & NCT00393029 & $\begin{array}{l}\text { Not reported } \\
\quad(n=11)\end{array}$ & SAE 0/11 & $N / A$ \\
\hline pp65 & CMV & HLA-A*0201 & Suspended & NCT02988258 & $\mathrm{N} / \mathrm{A}$ & $\mathrm{N} / \mathrm{A}$ & $\mathrm{N} / \mathrm{A}$ \\
\hline PRAME & $\begin{array}{l}\text { Myeloid and lymphoid } \\
\text { neoplasms }\end{array}$ & $\begin{array}{l}\text { HLA-A*0201 } \\
\text { (phase I) }\end{array}$ & Recruiting & NCT03503968 & $\mathrm{N} / \mathrm{A}$ & $\mathrm{N} / \mathrm{A}$ & N/A \\
\hline \multirow{2}{*}{ TIL 1383I } & Melanoma & HLA-A2 & Recruiting & NCT02870244 & $\mathrm{N} / \mathrm{A}$ & $N / A$ & $N / A$ \\
\hline & Melanoma & HLA-A2 & $\begin{array}{c}\text { Active, } \\
\text { not recruiting }\end{array}$ & NCT01586403 & PR 1/3 & SAE $0 / 3$ & 135 \\
\hline \multirow{4}{*}{ WT1 } & $\mathrm{AML}^{+}$and $\mathrm{CML}^{++}$ & HLA-A*0201 & Completed & NCT01621724 & $\mathrm{N} / \mathrm{A}$ & $\mathrm{N} / \mathrm{A}$ & $\mathrm{N} / \mathrm{A}$ \\
\hline & $\mathrm{MDS}^{+++}$and $\mathrm{AML}^{+}$ & HLA-A*0201 & Completed & NCT02550535 & $N / A$ & $\mathrm{~N} / \mathrm{A}$ & $N / A$ \\
\hline & Acute myeloid leukaemia & HLA-A*0201 & Recruiting & NCT02770820 & $\mathrm{N} / \mathrm{A}$ & $\mathrm{N} / \mathrm{A}$ & $\mathrm{N} / \mathrm{A}$ \\
\hline & Non-small cell lung cancer & HLA-A*0201 & $\begin{array}{c}\text { Active, } \\
\text { not recruiting }\end{array}$ & NCT02408016 & $\mathrm{N} / \mathrm{A}$ & $N / A$ & $\mathrm{~N} / \mathrm{A}$ \\
\hline
\end{tabular}

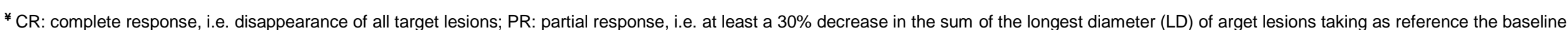
sum LD.

\# Reference for clinical trial data only.

${ }^{+}$AML: Acute myeloid leukaemia; ${ }^{++}$CML: Chronic myeloid leukaemia; ${ }^{++}$MDS: Myelodysplastic syndromes. 


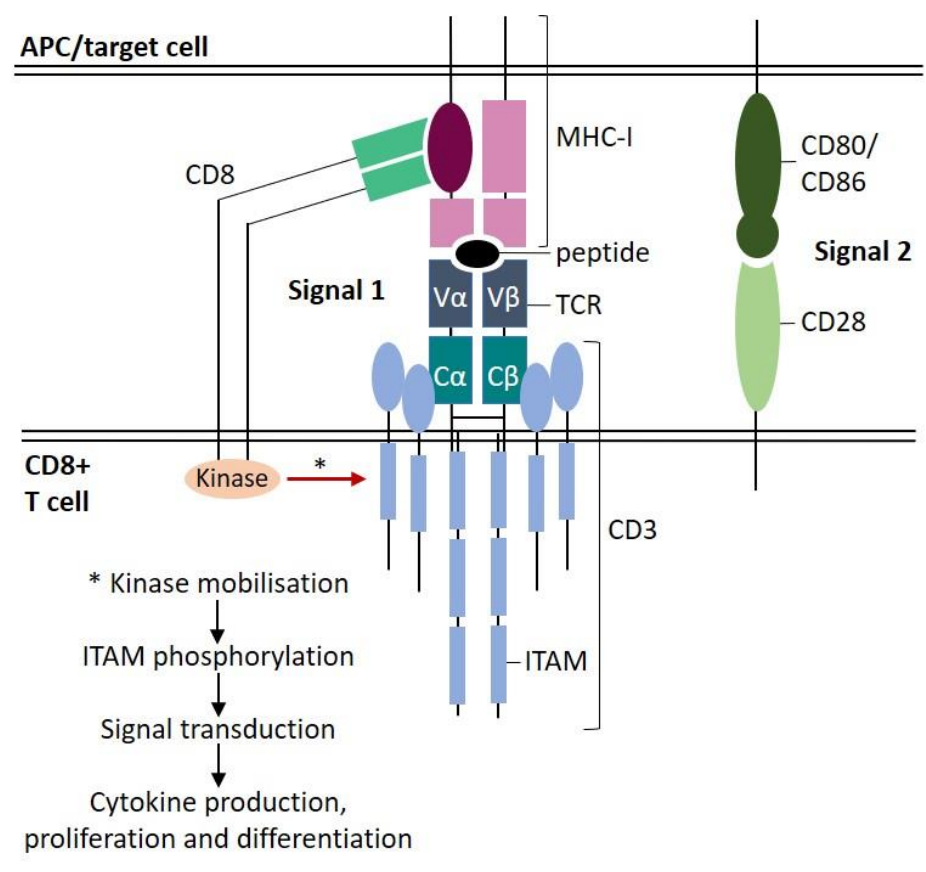

Figure 1. TCR structure and signalling. T cell activation is an antigen-dependent process that leads to proliferation and differentiation of naïve $T$ cells into effector cells. This process requires primary and co-activating signals triggering intracellular phosphorylation cascades and new gene expression.

$\mathrm{CD}^{+} \mathrm{T}$ cell activation is shown as an example. Signal 1 occurs when the TCR binds a foreign antigen presented by an MHC-I molecule on the surface of an APC/target cell and the T cell coreceptor (CD8) binds the MHC-I molecule. Signal 2 ensues, with T cell co-activating molecules (CD28) binding costimulatory proteins (CD80/CD86) on the APC/target cell. CD8-associated kinases are then brought into proximity of the CD3 complex and phosphorylate the ITAMs, which then interact with other kinases, promoting signal transduction resulting in cytokine production, as well as cell proliferation and differentiation.

Instructions for printing: to be printed in colour. 


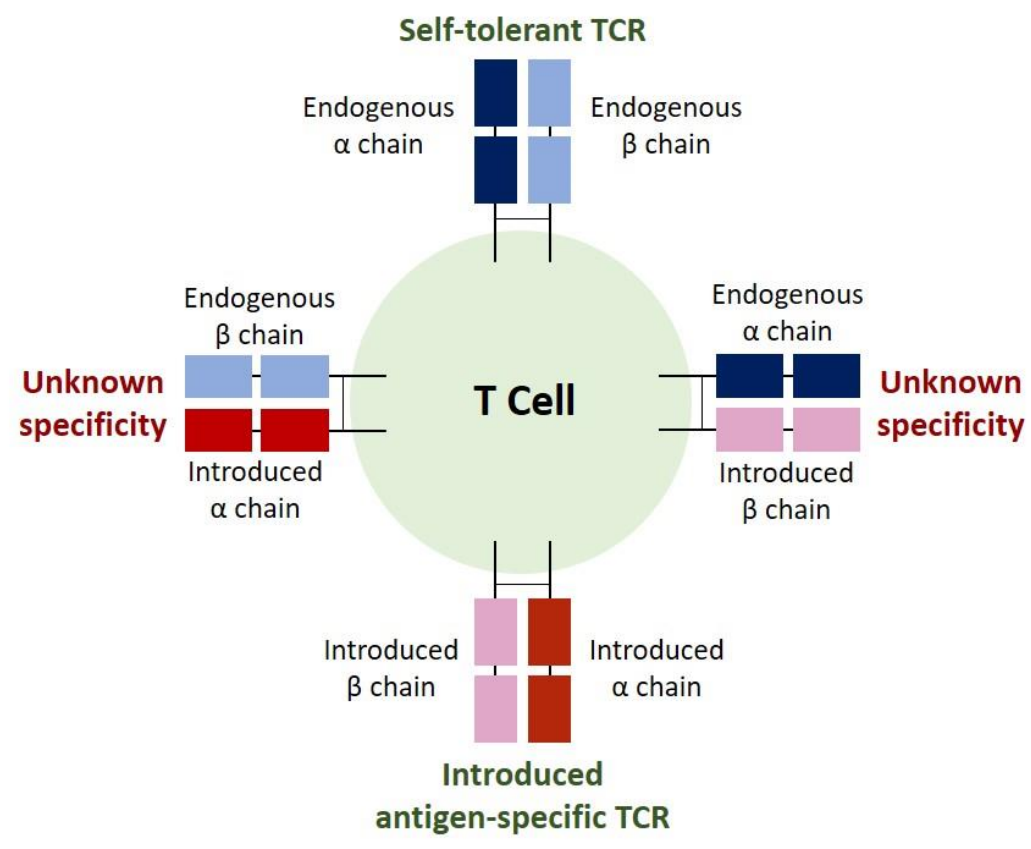

Figure 2. TCR chain mispairing. The presence of endogenous $\alpha$ and $\beta$ chains renders the cells able of expressing four different TCRs, only one of which possessing the desired specificity. TCRs of unknown specificity generated by the combination of endogenous and introduced $\alpha$ and $\beta$ chains may be autoreactive and reduce specific TCR pairing. Adapted from Thomas S, Stauss HJ \& Morris EC, Immunology 2010.

Instructions for printing: to be printed in colour. 


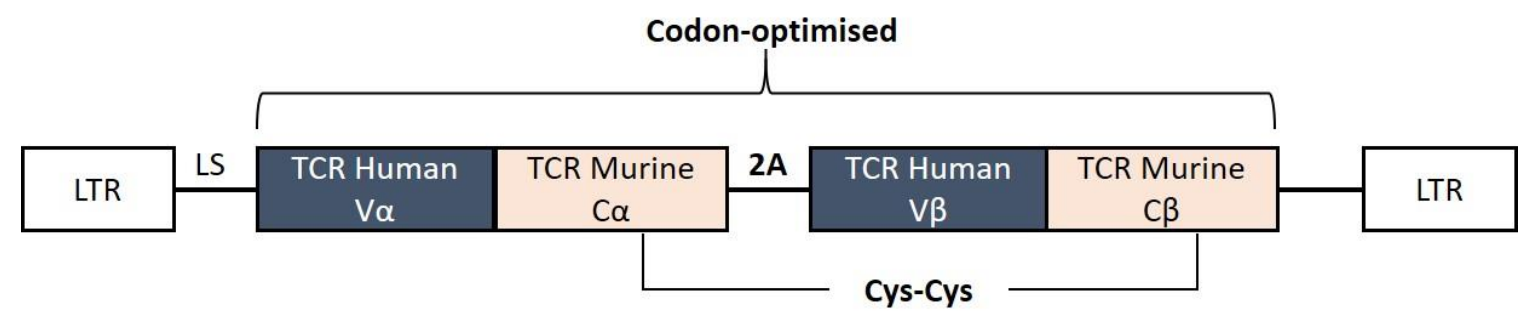

Figure 3. Schematic representation of the retroviral vector used for clinical trial NCT02988258. LTR: long terminal repeat (myeloproliferative sarcoma virus promoter); LS: leader sequence; TCR Human $V \alpha$ : codon-optimised $\alpha$ chain variable region of human CMVpp65-specific TCR; TCR Murine C $\alpha$ : codonoptimised $\alpha$ chain constant region of murine TCR; TCR Human V $\beta$ : codon-optimised $\beta$ chain variable region of human CMVpp65-specific TCR; TCR Murine C $\beta$ a: codon-optimised $\beta$ chain constant region of murine TCR; $2 \mathrm{~A}$ : self-cleaving $2 \mathrm{~A}$ sequence derived from porcine teschovirus; $\mathrm{Cys}-\mathrm{Cys}$ : additional disulphide bond.

Instructions for printing: to be printed in colour. 